\title{
The biology of long-term denervated skeletal muscle
}

\author{
Bruce M. Carlson
}

Institute of Gerontology, University of Michigan, Ann Arbor, Michigan, USA

\begin{abstract}
This review concentrates on the biology of long-term denervated muscle, especially as it relates to newer techniques for restoring functional mass. After denervation, muscle passes through three stages: 1) immediate loss of voluntary function and rapid loss of mass, 2) increasing atrophy and loss of sarcomeric organization, and 3) muscle fiber degeneration and replacement of muscle by fibrous connective tissue and fat. Parallel to the overall program of atrophy and degeneration is the proliferation and activation of satellite cells, and the appearance of neomyogenesis within the denervated muscle. Techniques such as functional electrical stimulation take advantage of this capability to restore functional mass to a denervated muscle.
\end{abstract}

Key Words: skeletal muscle, long-term denervation

Eur J Trans Myol - Basic Appl Myol 2014; 24 (1): 5-11

In the absence of innervation, skeletal muscle undergoes an inexorable course of atrophy, leading finally to a state in which the functioning muscle tissue is largely replaced by fibrous connective tissue and fat, along with a scattering of extremely attenuated muscle fibers. $^{1-3}$ These muscle fibers are almost unrecognizable at the light microscopic level and are largely devoid of the ability to contract.

As a denervated muscle proceeds toward terminal atrophy, it passes through several recognizable stages, but the duration of these stages varies depending upon the species. In rats and most laboratory animals, the stages are measured in months, whereas human muscle requires years to pass through similar stages. Three main stages have been described for the progressive decline of denervated muscles. ${ }^{1,4}$ The first stage, which begins immediately after nerve section, is characterized by immediate loss of function, followed by rapid weight loss and muscle fiber atrophy. The second stage is characterized by increasingly severe muscle atrophy, including the loss of most sarcomeric organization. This is followed by a long third phase in which interstitial fibrosis and the appearance of adipocytes dominates the tissue architecture. The number of muscle fibers is greatly diminished, and those remaining bear little resemblance to normal muscle fibers. The post-denervation atrophy of the rat extensor digitorum longus muscle has been divided into three phases, based upon its restorative ability. ${ }^{5-7}$ During the first phase, lasting two months, the denervated muscle retains a capacity for restoration equal to that of a normal control muscle despite the fact that by the end of the first month the muscle has lost $90 \%$ of its original mass. The second phase (from 2-7 months), corresponding to the middle stage described by Lapolombella et al. ${ }^{4}$ is one in which the restorative ability progressively and dramatically declines. The terminal phase (beyond 7 months) is characterized by minimal restorative ability and deepening morphological atrophy along with tissue substitution.

In addition to their value in descriptive pathology, studies on the properties of long-term denervated muscle are clinically relevant because of the possibility of restoring denervated human muscle through either reinnervation or functional electrical stimulation. After a brief summary of short-term changes in denervated muscle, this review will concentrate principally on the biology of the later stages of postdenervation atrophy in skeletal muscle.

\section{Short-term changes in denervated muscle}

Following early descriptions by Gutmann and Zelená, ${ }^{3}$ Midrio $^{8}$ has provided an excellent contemporary account of changes and mechanisms underlying the denervation atrophy of muscle. Overall, the principal tissue dynamic seen in short-term denervated muscle is the progressive atrophy and functional deterioration of the original muscle fibers along with an activation of 


\section{The biology of long-term denervated muscle}

Eur J Trans Myol - Basic Appl Myol 2014; 24 (1): 5-11

the capability of the denervated muscle for producing new muscle fibers.

Within days, atrophy of muscle fibers in rodents becomes measurable, but the nature of the atrophy depends upon the type of muscle fiber and the muscle itself. Slow muscles typically undergo gross atrophy more quickly than do fast muscles. In fast muscles of the rat, type II fibers undergo rapid atrophy, whereas type I fibers retain their cross-sectional areas for at least two months. ${ }^{9-12}$

At the individual muscle fiber level, the initial stages of atrophy are characterized by the preservation of sarcomeric structure, but as stage one merges into the second stage of atrophy, ultrastructural changes become increasingly prominent. ${ }^{8,9,13,14}$ These include a loss of myofibrillar alignment, as evidenced by disruption of registration at the Z-line, and the loss of individual actin and myosin filaments. Changes in size, number and orientation of components of the sarcoplasmic reticulum system reflect a structural basis for functional changes in the excitation-coupling system. ${ }^{15,16}$ Both numbers and the structural complexity of individual mitochondria are also progressively reduced. ${ }^{17,18}$ Data on the numbers of myonuclei per fiber during denervation atrophy vary greatly, ranging from reports of no change to a significant reduction. ${ }^{19-24}$ It appears that preservation of myonuclei is more likely to occur in atrophying muscles in the mouse and in the rat diaphragm, whereas reductions have been more generally reported in limb muscles of the rat. Such variation has added complexity to discussions about the importance of nuclear domains in muscle fibers. ${ }^{25}$

Muscle spindles persist after denervation. ${ }^{9,26}$ The rate of intrafusal fiber atrophy is less than that of extrafusal fibers, but differences between nuclear bag and chain fibers diminish as atrophy proceeds. Interestingly, the number of intrafusal fibers typically increases after denervation.

Within days after denervation in rodents, satellite cells become activated, and in fast limb muscles of rodents, their frequency trebles during the first two months. ${ }^{19}$, 27,28 This is a morphological reflection of a general activation of a myogenic program in denervated muscle. Molecular investigations show an early increase of myogenic regulatory factors during the early post-denervation period. ${ }^{29-32}$

Functional studies mirror the morphological changes outlined above. One of the earliest indications of denervation is the presence of spontaneous fibrillation activity. ${ }^{33,34}$ This is temporally correlated with the early post-denervation spread of acetylcholine receptors along the muscle fiber membrane ${ }^{35,36}$ and the general disruption of the sarcoplasmic reticulum. ${ }^{37-39}$

A dramatic reduction in tension produced by a stimulated denervated muscle occurs within days, with a relatively greater decrease seen in tetanic than in twitch tension. Changes in speeds of contraction vary considerably, depending upon the species, the muscle and the circumstances of stimulation. ${ }^{8}$ These are based on a number of factors, including the organization and types of contractile proteins.

At the tissue level, one of the most prominent changes during the first stage of denervation is seen in the capillary bed. Although paradoxically whole-muscle blood flow increases during the very early postdenervation period ${ }^{40}$ the weeks following denervation of rodent muscle see a substantial decrease in capillarity. ${ }^{41-43}$ This is represented in both the capillary/muscle fiber ratio and total capillarity, and necrosis of capillaries has been demonstrated at both the light and electron microscopic levels. ${ }^{42-44}$ Fibrosis is minimal during the early post-denervation period, but within a week after denervation in mice significant numbers of bone marrow-derived cells, mainly macrophages, appear in both the postsynaptic and general interstitial regions. ${ }^{45}$ Growth factors secreted by these cells stimulate local fibroblasts to produce type I collagen, which progressively accumulates with increasing denervation time.

\section{Long-term changes in denervated muscle}

The biology of long-term denervated muscle is dominated by several main themes. First is the continuing atrophy and actual degeneration of original muscle fibers. Second is the replacement of muscle fiber mass by fat and fibrous connective tissue. Third is the dramatic loss of capillaries associated with the muscle fibers and degenerative changes within intramuscular nerve trunks. Fourth is the activation of satellite cells and the appearance of newly forming muscle fibers. Detailed studies on these processes have been carried out largely on laboratory animals, but in recent years an increasing clinical literature has allowed meaningful comparisons between long-term denervated muscles in humans and laboratory animals. Although differences in the rate of atrophy between fast and slow muscles and similar muscles in different species have been well documented, $\mathrm{Wu}$ et al. ${ }^{46}$ have recently reported a more rapid rate of atrophy in denervated muscles of the hand than of the arm of rats. Following the rapid phase of muscle fiber atrophy seen during the first month after denervation in the rat, later post-denervation periods consist of major disorganization of the sarcomeric apparatus in most muscle fibers, although cross-sectional areas of type I fibers continue to be more resistant to atrophy than are type II fibers. ${ }^{9,10,14}$ A functional indication of the disorganization of the contractile apparatus of denervated muscle fibers is the report of Squecco et al. $^{47}$ who found residual contractility in only $8 \%$ of muscle fibers isolated from 16-week denervated rat soleus and tibialis anterior muscles and 5 and $3 \%$ respectively from 44 -week denervated muscles. These same authors noted that excitation-contraction coupling is minimally impaired before 13 weeks, but 


\section{The biology of long-term denervated muscle}

Eur J Trans Myol - Basic Appl Myol 2014; 24 (1): 5-11

that significant changes in the $\mathrm{T}$ tubule system occur after four months. Considerably reduced energy metabolism is strongly related to the significant decline in mitochondrial number and complexity. Although frankly necrotic muscle fibers can be seen as early as two months post-denervation in the rat, ${ }^{10,48}$ such changes are much more prominent after the first year. In contrast, rabbit muscle, denervated up to year, exhibits atrophy but not necrosis of muscle fibers. ${ }^{49}$ Myonuclear loss in the denervated rat EDL muscle proceeds at a rate of about one nucleus per day over the first seven months of denervation. ${ }^{19}$ Both apoptotic 50 and non-apoptotic mechanisms ${ }^{27,48}$ have been proposed. As the time of denervation and the severity of atrophy progresses, a significant distribution in the arrangement of the nuclei takes place. In rat muscle denervated for more than seven months, it is common to find severely atrophic fibers, the outlines of which resemble a chain of elongated beads. The bulging part of an individual bead-like compartment is anucleate, and at the attenuated neck between cytoplasmic beads is an aggregation of 5-15 nuclei. ${ }^{19,51}$ Neither the mechanism underlying the nuclear redistribution nor the functional significance of this arrangement is understood, but its appearance in both rat and human muscle suggests that it is not an uncommon phenomenon. In contrast to rat limb muscles, myonuclei do not appear to decrease in limb muscles of the mouse up to 4 months after denervation. ${ }^{23}$

Another poorly understood phenomenon is the presence of large muscle fibers in very long-term denervated muscle. Sometimes seen in rats, it is particularly prominent in human muscle denervated for more than three years. ${ }^{52}$ Although these large muscle fibers have often been considered to be products of selective reinnervation, they do not typically possess ultrastructural features of reinnervated muscle fibers. Reinnervation is unlikely to account for many instances of the presence of such large myofibers.

One of the most characteristic features of very longterm denervated muscles, whether in laboratory animals or in humans, are massive fibrosis and the presence of fat cells within the interstitium. ${ }^{9,10,53,54}$ Individual atrophic muscle fibers are typically embedded in dense mats of collagen fibers and are frequently not associated with capillaries. Adipocytes tend to occur in clumps with no obvious geometrical relationship to the atrophic muscle fibers. In the rat, the adipocyte presence is greater in red than in white muscles. ${ }^{55}$

Capillary loss is one of the most prominent features of denervated muscle, with a $90 \%$ reduction in capillary/muscle fiber ratio by 18 months in rat fast muscle. ${ }^{42}$ The rate of loss is most rapid between two and four months of denervation. The rate and extent of capillary loss is greater around type II than type I muscle fibers, suggesting that this could be related to the more rapid atrophy of type II than type I fibers.
Mitochondrial numbers, especially in type I fibers, are dramatically reduced. The corresponding compromise in oxidative metabolism, along with the production of reactive oxygen species in denervated muscle, ${ }^{56}$ may play a significant role in the overall atrophic process. One of the prominent features associated with capillary loss is the number of muscle fibers that are not associated with capillaries, but are rather surrounded by dense masses of collagen fibers. The source of these collagen fibers is not clear, especially in view of the low number of fibroblasts seen in atrophying muscle. The morphological evidence strongly suggests that many of the atrophying muscle fibers are situated in a highly hypoxic environment because of the linear distance between the muscle fibers and the nearest capillaries. A prominent feature of the diminution of the capillary network in a denervated muscle is the patchy distribution of vascular changes, with some areas of a muscle much more severely affected than others at a given time. The basis for this is not known. A factor of considerable importance in denervated muscle is the condition of distal nerve channels within the muscle, because of their role in guiding regenerating nerve fibers to muscle fibers. The large literature on changes in distal trunks of transected nerves will not be reviewed here. ${ }^{57-61}$ After an early period of activation, Schwann cells undergo progressive atrophy. Many of them disappear as the endoneurial spaces become filled with increasing deposits of collagen fibers. Nevertheless, some Schwann cells within small nerve branches can survive and produce some neurotrophic molecules for more than two years after denervation. ${ }^{57,62}$ A critical issue for reinnervation is whether a small population of competent Schwann cells can compensate for the mechanical obstruction of the nerve channels by collagen fibers and the attendant hypoxic environment resulting from capillary depletion.

\section{Regeneration and myogenesis in long-term denervated muscle and during aging}

Traditionally, denervated muscle has been thought to undergo an inexorable atrophic decline, leading to an essentially functionless remnant of severely atrophic muscle fibers embedded in a dense matrix of fibrous connective tissue and fat. Research over the past two decades, however, has shown a surprising amount of developmental potential and activity. The basis for this is activation of the satellite cell population. Within days after denervation the satellite cell population begins to increase until by two months in the rat the number of satellite cells per muscle fiber is approximately three times control values. ${ }^{19}$ From this peak, the satellite cell population undergoes a steady decline even into old age. The increase in satellite cell numbers is accompanied by morphological signs of satellite cell activation and patterns of gene activity characteristic of a myogenic response. ${ }^{4,28,31}$ However, 


\section{The biology of long-term denervated muscle}

Eur J Trans Myol - Basic Appl Myol 2014; 24 (1): 5-11

by the time denervation is well advanced (e.g. $>2$ years), satellite cell numbers fall well below control levels, even when advanced age is taken into consideration. $^{19,63}$ Nevertheless, despite the reduced population of satellite cells, both MyoD and myogenin mRNA and proteins are expressed at elevated levels. ${ }^{63}$ In denervated human laryngeal muscle, Donghui et al. $^{64}$ found upregulation of MyoD and myogenin up to two years post-denervation, but after that time levels were no higher than those in control muscle tissue.

A tangible result of the satellite cell activity in longterm denervated muscle is the formation of new muscle fibers among the atrophying original muscle fibers. ${ }^{51,53,64}$ In non-stimulated muscle, these muscle fibers remain very small and undergo poor differentiation. $\underline{65}$ In addition, these regenerated muscle fibers are not associated with satellite cells in the rat. ${ }^{63}$ Available evidence suggests that in long-term denervated muscle there are repeated cycles of neomyogenesis and subsequent atrophy of these newly formed muscle fibers.

Several laboratories have demonstrated a substantial regenerative capacity in denervated muscle after some form of injury, whether induced by myotoxic agents or ischemia. ${ }^{66-68}$ Using a grafting model, Billington and Carlson $^{69}$ found improved regeneration if the grafted muscles were treated with bupivacaine as compared with untreated grafted muscles.

The formation of new muscle fibers in long-term denervated muscles is paralleled by the formation of new muscle fibers in control muscles of extremely old rats. $^{70,71}$ This could be a reflection of the greatly diminished innervation in the muscles of very old rats. Nevertheless, the reactions of satellite cells in 24month-old rats to denervation is very similar to that seen in young animals, ${ }^{72}$ suggesting that aging per se does not repress the capacity of satellite cells to become activated after denervation.

\section{The restoration of long-term denervated muscle in humans}

Two fundamental strategies have been employed to restore function to long-term denervated muscle. The classical surgical technique has been to facilitate reinnervation through nerve repair. ${ }^{73,74}$ Although successful for the repair of short-term denervated muscle if the distance required for axonal regeneration is not too great, the recovery of contractile function is typically greatly diminished if regenerating motor axons do not contact denervated muscle fibers within 12-18 months. Because of this limitation, considerable effort has been expended in devising means of restoring long-term denervated human muscle by functional electrical stimulation (FES).

Techniques of FES in humans have now developed to the point where substantial maintenance and quantifiable improvement of muscle fiber structure and function can be produced if a treatment regimen is instituted within two years. ${ }^{51,53,75,76}$ The reduction of effectiveness of this technique after two years of denervation corresponds to the substantially poorer recovery of rat muscle after 4-7 months of denervation. These post-denervation times are roughly parallel in terms of the cellular and tissue architecture of the two species. Human muscle denervated for shorter periods still maintains a metabolic profile that is more compatible with restoration. ${ }^{77}$ Yet, the exact nature of the factor(s) inhibiting full restoration remains incompletely understood.

\section{Summary}

Over the previous two decades our understanding of the biology of long-term denervated muscle has undergone a dramatic change. Before that time, denervated muscle was generally considered to progress inexorably down a long course of atrophy and degeneration, with replacement of functioning muscle mass by dense sheets of connective tissue and fat. It is now apparent that denervated muscle exhibits another dimension, namely a system that has both the capability and actuality of participating in active myogenesis. Left alone, this developmental capability is of little practical use, but when regeneration is stimulated, either by myotoxic agents or through FES, a remarkable degree of functional restoration can be attained. Nevertheless, there are presently limits on the capacity of denervated muscle for functional return. In human muscle, at roughly two years - the boundary between a principally atrophic response to denervation and the phase of degeneration - the success of restorative programs becomes sharply diminished. This corresponds to the period of from 4-7 months postdenervation in the rat. The underlying basis for this reduction in restorative capacity remains to be elucidated.

\section{Acknowledgements}

This paper is dedicated to Ugo Carraro in honor of his retirement and of his passion for understanding the mysteries of long-term denervated muscle.

\section{Corresponding Author}

Bruce M. Carlson, 1345 Waterford Drive, Golden Valley, MN 55422, USA. Tel. +1 763-205-3789

E-mail: brcarl@umich.edu

\section{References}

1. Tower S. Atrophy and degeneration in skeletal muscle. Am J Anat 1935;56:1-56.

2. Gutmann E. Effect of delay of innervation on recovery of muscle after nerve lesions. J Neurophysiol 1948;11:279-94.

3. Gutmann E, Zelená J. Morphological changes in denervated muscles. In: Gutmann E, ed. The denervated muscle. Prague: Publishing House of 
The biology of long-term denervated muscle

Eur J Trans Myol - Basic Appl Myol 2014; 24 (1): 5-11

the Czechoslovak Academy of Sciences; 1962. pp 57-102.

4. Lapalombella R, Kern $\mathrm{H}$, Adami $\mathrm{N}$ et al. Persistence of regenerative myogenesis in spite of down-regulation of activity-dependent genes in long-term denervated rat muscle. Neurol Res 2008;30:197-206.

5. Gulati AK. Restoration of denervated skeletal muscle transplants after reinnervation in rats. Restor Neurol Neurosci 1990; 2:23-29.

6. Carlson BM, Billington L, Faulkner J. Studies on the regenerative recovery of long-term denervated muscle in rats. Restor Neurol Neurosci 1996; 10:77-84.

7. Carlson BM, Borisov AB, Dedkov EI et al. The biology and restorative capacity of long-term denervated skeletal muscle. Basic Appl Myol 2002;12:249-56.

8. Midrio M. The denervated muscle: facts and hypotheses. A historical review. Eur J Appl Physiol 2006;98:1-21.

9. Lu D-X, Huang S-K, Carlson BM. Electron microscopic study of long-term denervaed rat skeletal muscle. Anat Rec 1997; 248:355-65.

10. Borisov AB, Dedkov EI, Carlson BM. Interrelations of myogenic response, progressive atrophy of muscle fibers, and cell death in denervated skeletal muscle. Anat Rec 2001; 264:203-18.

11. Karpati G, Engel W. Correlative histochemical study of skeletal muscle after suprasegmental denervation, peripheral nerve section and skeletal fixation. Neurology 1968;18:681-92.

12. Davis HL, Kiernan JA. Neurotrophic effects of sciatic nerve extract on denervated extensor digitorum longus muscle in the rat. Exp Neurol 1980;69:124-34.

13. Vrbova FG, Gordon T, Jones R. Nerve-muscle interactions. London, Chapman and Hall; 1995.

14. Schmalbruch H, Al-Amood WS, Lewis DM. Morphology of long-term denervated rat soleus muscle and the effect of chronic electrical stimulation. J Physiol 1991;441:233-41.

15. Salvatori $S$, Damiani $E$, Zorzato $F$ et al. Denervation-induced proliferative changes of triads in rabbit skeletal muscle. Muscle Nerve 1988;11:1246-59.

16. Takekura H, Kasuga N, Kitada K, Yoshioka T. Morphological changes in the triads and sarcoplasmic reticulum of rat slow and fast muscle fibres following denervation and immobilization. J Muscle Res Cell Motil 1996; 17:391-400

17. Gauthier GF, Dunn RA. Ultrastructural and cytochemical features of mammalian skeletal muscle fibres following denervation. J Cell Sci $1973 ; 12: 525-47$
18. Manolov S, Ovtscharoff W. Ultrastructural changes in the muscle cells of denervated muscles of rat. Mikrosk Anat Forsch 1974;88:726-44.

19. Viguie CA, Lu D-X, Huang S-K et al. Quantitative study of the effects of long-term denervation on the extensor digitorum longus muscle of the rat. Anat Rec 1997;248:346-54.

20. Hikida RS, Van Nostran S, Murray JD et al. Myonuclear loss inn atrophied soleus muscle fibers. Anat Rec 1997;247:350-4.

21. Schmalbruch H, Lewis DM. Dynamics of nuclei of muscle fibers and connective tissue cells in normal and denervated rat muscles. Muscle Nerve 2000; 23:617-26.

22. Aravamudan B, Mantilla CB, Zhan W-Z, Sieck GC. Denervation effects on myonuclear domain size of rat diaphragm fibers. J Appl Physiol 2006; 100:1617-22.

23. Wada K-I, Takahashi H, Katsuta S, Soya H. No decrease in myonuclear number after long-term denervation in mature mice. Am J Physiol Cell Physiol 2002;283:C484-C8.

24. Zhong H, Roy RR, Siengthai B, Edgerton VR. Effects of inactivity on fiber size and myonuclear number in rat soleus muscle. J Appl Physiol 2005;99:1494-99.

25. Allen DL, Roy RR, Edgerton VR. Myonuclear domains in muscle adaptation and disease. Muscle Nerve 1999; 22:1350-60.

26. Zelená J. Nerves and mechanoreceptors. London: Chapman \& Hall; 1994.

27. de Castro Rodrigues A, Schmalbruch H. Satellite cells and myonuclei in long-term denervated rat muscles. Anat Rec 1995;243:430-7.

28. Chen D, Chen S, Wang W et al. Modulation of satellite cells in rat facial muscle following denervation and delayed reinnervation. Acta OtoLaryngol 2010;130:1411-20.

29. Adams L, Carlson BM, Henderson L, Goldman D. Adaptation of nicotinic acetylcholine receptor, myogenin and MRF4 gene expression to longterm muscle denervation. J Cell Biol 1995; 131:1341-49.

30. Khalyfa A, Carlson BM, Dedkov EI, Wang E. Changes in protein levels of elongation factors, eEF1A1 and eEF1A-2/S1, in long-term denervated rat muscle. Restor Neurol Neurosci 2003;21:47-53.

31. Batt J, Bain J, Goncalves J et al. Differential gene expression profiling of short and long term denervated muscle. FASEB J 2006;20:115-7.

32. Jeng S-F, Rau C-S, Liliang P-C et al. Profiling muscle-specific microRNA expression after peripheral denervation and reinnervation in a rat model. J Neurotrauma 2009;26:2345-53.

33. Hník P, Skorpil V. Fibrillation activity in denervated muscle. In: Gutmann E, ed. The denervated muscle. Prague: Publishing House of 


\section{The biology of long-term denervated muscle}

Eur J Trans Myol - Basic Appl Myol 2014; 24 (1): 5-11

the Czechoslovak Academy of Sciences; 1962. pp. 136-50.

34. Midrio $\mathrm{M}$, Caldesi-Valeri $\mathrm{V}$, Princi $\mathrm{T}$ et al. Differential effects of disuse preceding denervation on the onset and development of fibrillation in fast and slow muscles. Experientia 1977;33:209-11.

35. Axelsson J, Thesleff S. A study of supersensitivity in denervated mammalian skeletal muscle. J Physiol 1959;147:178-93.

36. Bandi E, Bernareggi A, Grandolfo $M$ et al. Autocrine activation of nicotinic acetylcholine receptors contributes to $\mathrm{Ca} 2+$ spikes in mouse myotubes during myogenesis. J Physiol 2005; 568:171-80.

37. Lewis DM. The effect of denervation on the mechanical and electrical responses of fast and slow mammalian twitch muscle. J Physiol 1972; 222:51-75.

38. Dulhunty AF. Excitation-contraction coupling and contractile properties in denervated rat EDL and soleus muscles. J Muscle Res Cell Motil 1985;6:207-25.

39. Midrio M, Danieli-Betto $\mathrm{D}$, Betto $\mathrm{R}$ et al. Cordotomy-denervation interactions on contractile and myofibrillar properties of fast and slow muscles in the rat. Exp Neurol 1988; 100:216-36.

40. Hudlická O. Blood flow and oxygen consumption in muscles after section of ventral roots. Circ Res 1967; 20:570-7.

41. Chernukh AM, Alekseeva NN. Changes in the capillary bed of skeletal muscle at various times after denervation. Byull Eksp Biol Med 1975: 80:12-6.

42. Borisov AB, Huang S-K, Carlson BM. Remodeling of the vascular bed and progressive loss of capillaries in denervated skeletal muscle. Anat Rec 2000;258:292-304.

43. Tyml K, Mathieu-Costello O. Structural and functional changes in the microvasculature of disused skeletal muscle. Front Biosci 2001;6:D45-52.

44. Carpenter S, Karpati G. Necrosis of capillaries in denervation atrophy of human skeletal muscle. Muscle Nerve 1982;5:250-4.

45. Mochizuki Y, Ojima K, Uezumi A et al. Participation of bone marrow-derived cells in fibrotic changes in denervated skeletal muscle. Am J Pathol 2005;166:1721-32.

46. Wu J-X, Chen L, Ding F, Gu Y-D. A rat model study of atrophy of denervated musculature of the hand being faster than that of denervated muscles of the arm. J Muscle Res Cell Motil 2013;34:1522.

47. Squecco R, Carraro U, Kern H et al. A subpopulation of rat muscle fibers maintains an assessable excitation-contraction coupling mechanism after long-standing denervation despite lost contractility. J Neuropathol Exp Neurol 2009;68:1256-68.

48. Borisov AB, Carlson BM. Cell death in denervated skeletal muscle is distinct from classical apoptosis. Anat Rec. 2000:258:305-318.

49. Ashley Z, Sutherland H, Lanmüller $H$ et al. Atrophy, but not necrosis, in rabbit skeletal muscle denervated for periods up to one year. Am J Physiol Cell Physiol 2007;292:C440-C51.

50. Siu PM. Muscle apoptotic response to denervation, disuse, and aging. Med Sci Sports Exerc 2009;41:1876-86.

51. Rossini K, Zanin ME, Podhorska-Okolow M, Carraro U. To stage and quantify regenerative myogenesis in FES-induced functional recovery of human long-term permanent denervated muscle. Basic Appl Myol 2002;12:277-86.

52. Biral D, Kern H, Adami N et al. Atrophy-resistant fibers in permanent peripheral denervation of human skeletal muscle. Neurol Res 2008;30:13744.

53. Carraro U, Rossini K, Mayr W, Kern H. Muscle fiber regeneration in human permanent lower motoneuron denervation: Relevance to safety and effectiveness of FES-training, which induces muscle recovery in SCI subjects. Artif Organs 2005;29:187-91.

54 Kern H, Boncompagni S, Rossini K et al. Longterm denervation in humans causes degeneration of both contractile and excitation-contraction coupling apparatus, which is reversible by functional electrical stimulation (FES): A role for myofibrillar regeneration? J Neuropath Exp Neurol 2004;63:919-31.

55 de Castro Rodrigues A, Andreo JC, Rosa GM et al. Fat cell invasion in long-term denervated skeletal muscle. Microsurgery 2007;27:664-7.

56 Abruzzo PM, Ditullio S, Marchionni C et al. Oxidative stress in the denervated muscle. Free Radical Res 2010;44:563-76.

57. Bradley JL, Abernathy DA, King RH et al. Neural architecture in transected rabbit sciatic nerve after prolonged nonreinnervation. J Anat 1998;192:529-38.

58. Frostick SP, Yin Q, Kemp GJ. Schwann cells, neurotrophic factors, and peripheral nerve regeneration. Microsurgery 1998; 18:397-405.

59. Fu SY, Gordon T. Contributing factors to poor functional recovery after delayed nerve repair: prolonged denervation. J Neurosci 1995; 15:3886-95.

60. Roytta M, Salonen V. Long-term endoneurial changes after nerve transection. Acta Neuropathol 1988;76:35-45.

61. Sulaiman OAR, Gordon T. Effects of short- and long-term Schwann cell denervation on peripheral 


\section{The biology of long-term denervated muscle}

Eur J Trans Myol - Basic Appl Myol 2014; 24 (1): 5-11

nerve regeneration, myelination, and size. Glia 2000;32:234-46.

62. Dedkov EI, Kostrominova TY, Borisov AB and Carlson BM. Survival of Schwann cells in chronically denervated skeletal muscles. Acta Neuropathol 2002;103:565-74.

63. Dedkov EI, Kostrominova TY, Borisov AB, Carlson BM. Reparative myogenesis in long-term denervated skeletal muscles of adult rat results in a reduction of the satellite cell population. Anat Rec 2001;263:139-54.

64. Donghui C, Shicai C, Wei W et al. Functional modulation of satellite cells in long-term denervated human muscle. Laryngoscope 2009; 120:353-8.

65. Borisov AB, Dedkov EI, Carlson BM. Differentiation of activated satellite cells in denervated muscle following single fusions in situ and in cell culture. Histochem Cell Biol 2005; 124:13-23.

66. Carraro U, Morale D, Mussini I et al. Chronic denervation of rat hemidiaphragm: Maintenance of fiber heterogeneity with associated increasing uniformity of myosin isoforms. J Cell Biol 1985; 100:161-174.

67. Mussini I, Favaro G, Carraro U. Maturation, dystrophic changes and the continuous production of fibers in skeletal muscle regenerating in the absence of nerve. J Neuropathol Exp Neurol 1987;46:315-31.

68. Carlson BM, Billington L, Faulkner JA. Studies on the regenerative recovery of long-term denervated muscle in rats. Restor Neurol Neurosci 1996;10:77-84.
69. Billington L, Carlson BM. The recovery of longterm denervated rat muscles after Marcaine treatment and grafting. J Neurol Sci 1996; 144:147-55.

70. Carlson BM, Dedkov EI, Borisov AB, Faulkner JA. Skeletal muscle regeneration in very old rats. J Gerontol Biol Sci 2001; 56A:B224-B233.

71. Dedkov EI, Kostrominova TY, Borisov AB, Carlson BM. MyoD and myogenin protein expression in skeletal muscles of senile rats. Cell Tissue Res 2003; 311:401-416.

72. Dedkov EI, Borisov AB, Wernig A, Carlson BM. Aging of skeletal muscle does not affect the response of satellite cells to denervation. J Hiistochem Cytochem 2003; 51:853-863.

73. Bateman JE. Trauma to nerves in limbs. Philadelphia, Saunders, 1962.

74. Sunderland S. Nerves and nerve injuries, 2nd ed. Edinburgh, Churchill Livingstone, 1978.

75. Boncompagni S, Kern $\mathrm{H}$, Rossini $\mathrm{K}$ et al. Structural differentiation of skeletal muscle fibers in the absence of innervation in humans. PNAS 2007; 104:19339-44.

76. Kern H, Salmons S, Mayr W et al. Recovery of long-term denervated human muscles induced by electrical stimulation. Muscle Nerve 2005; 31:98101.

77. Mancinelli $\mathrm{R}$, Kern $\mathrm{H}$, Fulle $\mathrm{S}$ et al. Transcriptional profile of denervated vastus lateralis muscle derived from a patient 8 months after spinal cord injury: A case report. J Immunopathol Pharmacol 24:749-59. 